\title{
Epidemia e memória no discurso jornalístico sobre a dengue
}

\section{Luiz Marcelo Robalinho Ferraz e Isaltina Maria de Azevedo Mello Gomes}

\section{Resumo}

Este artigo apresenta os resultados da dissertação de mestrado Epidemia e memória: narrativas jornalísticas na construção discursiva sobre a dengue. Concluída na Universidade Federal de Pernambuco (UFPE) em 2010, a pesquisa teve 0 objetivo de avaliar os sentidos produzidos pela imprensa pernambucana a respeito da dengue, doença que vem afetando mais os brasileiros. Tendo como ponto de partida a epidemia explosiva de 2002, selecionamos os 291 textos publicados pelo Jornal do Commercio em 2002, 2004, 2006 e 2008 sobre a doença. Neles, buscamos identificar o papel da memória discursiva e a presença do interdiscurso, bem como aprofundar as análises em torno da narrativa jornalística. Constatamos que o noticiário é constituído com base em noções seculares de medo, mal, morte, risco e epidemia. Além disso, a estrutura narrativa e a inserção dos atores que falam sobre a dengue são condicionadas ao contexto da dengue.

\section{Palavras-chave}

Dengue. Epidemia. Interdiscurso. Memória Discursiva. Narrativa Jornalística.

\section{Luiz Marcelo Robalinho Ferraz |}

marcelorobalinho@yahoo.com.br

Doutorando em Informação e Comunicação em Saúde pela Fundação Oswaldo Cruz (PPGICS-Fiocruz), mestre em Comunicação pela Universidade Federal de Pernambuco (PPGCOM-UFPE) e jornalista.

\section{Isaltina Maria de Azevedo Mello Gomes |} isaltina@gmail.com

Doutora em Linguística pela Universidade Federal de Pernambuco. Professora de Jornalismo e do Programa de Pós-graduação em Comunicação da UFPE.

\section{Introdução}

Em 2002, Pernambuco vivenciou a maior epidemia de dengue da sua história, bem como o Brasil inteiro, devido à entrada do terceiro sorotipo do vírus (DENV-3) no país. Naquele ano, foram notificados 116.245 registros da doença no território pernambucano, sendo 96.470 confirmados como dengue clássica e 340 do tipo hemorrágico. Vinte pessoas morreram. Foi 0 segundo estado brasileiro com maior número de casos, perdendo apenas para o Rio de Janeiro ${ }^{1}$. 0 contexto de calamidade pública causado pela dengue levou a imprensa a noticiar amplamente 0 assunto, acompanhando dia após dia o desenrolar dos fatos.

Embora estivesse presente desde o período colonial, a dengue surgiu, de fato, e ficou conhecida no país com a reintrodução do Aedes aegypti (mosquito transmissor da febre amarela e da dengue), em 1976, levando à disseminação de diversas epidemias da segunda metade da década de 80 para cá. ${ }^{2}$ A aproximação e a presença cada vez maior da dengue no espaço 
geográfico das cidades nos últimos anos levaram a um envolvimento dos veículos de comunicação na divulgação de notícias sobre a virose, que nunca deixa de ser notícia por apresentar ciclos epidêmicos que atingem em maior ou menor grau a população, a depender da circulação viral e de condições ambientais que favoreçam a infecção.

Pela posição privilegiada que ocupa no espaço público, a mídia se configura num locus de constituição de sentidos importante, sendo considerada "o principal lugar de memória e/ ou de história das sociedades contemporâneas" (RIBEIR0, 2005, p. 115, grifos da autora). Em grande parte, as informações de que dispomos sobre a dengue advêm da divulgação dos media, tendo como base a fala de diferentes atores relacionados ao assunto: gestores públicos, médicos, cientistas, cidadãos e pacientes, só para citar os mais expressivos. Baseada nessas falas e na própria evolução da doença, a mídia vai construindo 0 seu discurso e consolidando o arcabouço de informações e valores que permeiam a dengue.
Pensando nisso, buscamos analisar os discursos produzidos pela imprensa pernambucana em 2002, 2004, 2006 e 2008 para compreensão dos efeitos de sentido, tomando a epidemia explosiva ${ }^{3}$ de 2002 como ponto de partida. Selecionamos as notícias publicadas no Jornal do Commercio do Recife, contabilizando um total de 291 textos, entre matérias, reportagens e notas. Escolhemos esse periódico por ser um dos três mais importantes no estado e com maior tiragem ${ }^{4}$. Para nós, a importância da pesquisa está em avaliar como se deu a construção dos dizeres jornalísticos sobre a dengue nos diferentes momentos a partir do arquivo escolhido. Sem se configurar num sistema unificador de tudo o que foi dito, 0 arquivo selecionado nos fez compreender as similaridades e possíveis diferenças dos múltiplos discursos, considerando-os como acontecimentos singulares dentro do universo discursivo, assim como são as epidemias, na concepção de Foucault $(2007,2006)$.

Segundo dados repassados pelo Ministério da Saúde para a nossa pesquisa, o estado do Rio de Janeiro apresentou 249.120 registros de pessoas com dengue em 2002. Em segundo lugar, veio Pernambuco e, em terceiro, a Bahia, com 77.592 casos. No Brasil, foram notificados no total 697.998 casos de dengue naquele ano.

0 custo crescente dos inseticidas, a resistência dos insetos ao veneno e a falta de continuidade dos programas de controle no mundo foram alguns dos fatores que concorreram para a reentrada do Aedes aegypti no Brasil. Com o golpe de 64, os programas foram centralizados, dificultando a operacionalidade das iniciativas e a articulação entre os estados. Tentativas de bloqueio foram feitas em 76, sem sucesso, devido ao retorno do Aedes em países vizinhos e a ocorrência de epidemias no Caribe e Américas Central e do Sul (DONALÍSIO, 1999).

0 que diferencia uma epidemia normal de uma epidemia explosiva é a velocidade de progressão da doença. Na explosiva, a manifestação da doença envolve em pouco tempo a quase totalidade das pessoas atingidas (ROUQUAYROL; ALMEIDA FILH0, 2003).

Segundo dados de maio de 2009 do Instituto Verificador de Circulação (www.ivc.org.br), o Jornal do Commercio possui uma média de circulação paga de 31.847 exemplares vendidos nas terças-feiras (dia de menor circulação), chegando a 65.028 exemplares no domingo (dia de maior circulação). 
Tabela 1 - Comparativo entre casos e matérias sobre dengue por período do ano, 2002-2008

\begin{tabular}{ccccccc}
\hline \multicolumn{5}{c}{ Notificações } & \multicolumn{3}{c}{ Textos } \\
\hline Ano & $1^{\circ}$ semestre & $2^{\circ}$ semestre & Total & $1^{\circ}$ semestre & $2^{\circ}$ semestre & Total \\
\hline 2002 & 111.729 & 4.419 & 116.148 & 119 & 25 & 144 \\
2004 & 4.676 & 1.650 & 6.326 & 5 & 6 & 11 \\
2006 & 12.934 & 5.695 & 18.629 & 6 & 24 & 30 \\
2008 & 38.079 & 2.934 & 41.013 & 94 & 12 & 106 \\
\hline & & 182.116 & 224 & 67 & 291 \\
\hline
\end{tabular}

Fonte: Site Jornal do Commercio (www.jc.com.br) / Secretaria de Saúde de Pernambuco.

Acontecimento epidemiológico que afeta 0 ecossistema da saúde, a epidemia se inscreve na memória pela imprevisibilidade. Falar de epidemia nos remete à desordem causada pelo caráter acidental da doença em larga escala na população, provocando mortes e afetando a rotina das cidades. Por isso, elas adquirem um sentido simbólico todo particular no cotidiano das sociedades contemporâneas a partir do momento em que se enfatiza discursivamente 0 "fantasma" do perigo.

Na área da saúde, o papel preponderante dos meios de comunicação irá se revelar nas situações coletivas, como as epidemias, quando a população se vê indistintamente ameaçada, isto é, a importância da imprensa, enquanto canal de informação/reivindicação, é mediatizada pelo caráter mais ou menos coletivo do agravo em questão, bem como pelo potencial de difusão social do problema (BARATA, 1990, p. 385).

Tomando por base a Análise do Discurso (AD), procuramos identificar o papel da memória discursiva e a presença do interdiscurso no material jornalístico analisado, pelo entrelaçamento existente entre os discursos, muitas vezes de diferentes campos, lugares e épocas. Como lidamos com o discurso da informação, procuramos também estabelecer uma ponte de contato com as teorias do jornalismo a fim de sedimentar as reflexões a respeito da narrativa construída pela imprensa. A partir da análise do material, constatamos que 0 noticiário a respeito da dengue é construído com base em noções ligadas a antigas doenças, tais como medo, mal, morte, risco e epidemia. Embora pareça à primeira vista um pouco distante da nossa realidade, essa memória secular está mais do que presente e é fundamental para compreendermos a relação das doenças do passado com as atuais na avaliação de sentidos. As análises revelaram ainda que esse dizer já sedimentado condiciona a inserção dos atores que falam sobre a dengue, conforme 0 contexto de controle ou descontrole da doença. 


\section{A memória da epidemia na agenda midiática}

Considerando a imprensa objeto cultural e espécie de "guardião da memória" na contemporaneidade, defendemos que a construção do discurso jornalístico sobre a dengue foi feita com base no presente e no passado das diferentes doenças infecciosas, tendo a epidemia como fio condutor para produção de sentidos. Falar em epidemia nunca foi algo positivo, a não ser quando 0 controle da moléstia é confirmado. Mas, ainda assim, o domínio costuma ser momentâneo, uma vez que o mundo nunca está livre totalmente da possibilidade de doenças e novas epidemias, inclusive da própria dengue.

Discursivamente, a memória tem um papel fundamental por trazer à tona traços existentes em outros enunciados, os chamados préconstruídos, que representam "uma construção anterior, exterior, independente por oposição ao que é construído na enunciação", remetendo assim ao que "cada um sabe" e, ao mesmo tempo, ao que "cada um pode ver" em uma situação determinada (COURTINE, 2009, p. 74-75). Nessa concepção, a memória está inscrita em práticas sociais que permitem compreender 0 funcionamento do discurso, o fato de um já-dito sustentar cada tomada de palavra e as próprias relações de sentido dos discursos, revelando 0 jogo de forças ante um discurso que surge como um "acontecimento a ser lido", segundo Pêcheux (2007, p. 52):
[...] a memória discursiva seria aquilo que, face a um texto que surge como acontecimento a ler, vem restabelecer os 'implícitos' (quer dizer, mais tecnicamente, os pré-construídos, elementos citados e relatados, discursos transversos, etc.) de que sua leitura necessita: a condição do legível em relação ao próprio legível.

Pêcheux (2008) denomina o discurso como estrutura e acontecimento de uma prática de linguagem que alia atualidade e memória ao mesmo tempo. Para ele, a memória sempre é perturbada a cada acontecimento discursivo novo, desmanchando a "regularização" existente e fazendo surgir um novo sistema por meio de um jogo de forças "que visa manter uma regularização pré-existente com os implícitos que ela veicula" e, em sentido contrário, "perturbar a rede dos implícitos".

Refletir sobre o papel da memória no discurso jornalístico é também discutir a respeito da presença do interdiscurso, considerado para a $\mathrm{AD}$ como um conjunto de discursos que dialogam e se articulam entre si. No caso da dengue, refletir sobre 0 interdiscurso é avaliar como os sentidos foram produzidos com base nos dizeres já construídos a respeito de outras doenças infecciosas, sobretudo as transmitidas por mosquitos. Apesar de as moléstias terem características distintas, as noções que envolvem cada uma delas mobilizam o que chamamos de "redes partilhadas de memória" acerca das enfermidades em geral. Novos sentidos vão sendo produzidos com 
base nos já existentes, através de um processo interdiscursivo, que estabelece pontos de contato com outros campos, como o militar.

Tratar de memória e interdiscurso é falar inevitavelmente de esquecimento e lembrança, a possibilidade de considerar tudo o que foi dito e não-dito sobre as diferentes doenças, os dizeres lembrados e esquecidos em um discurso para dar significado às palavras do sujeito. No interdiscurso, o esquecimento faz parte do saber discursivo, mobilizando relações de sentido. Sobre 0 assunto, diz Orlandi que a noção de historicidade é fundamental para se compreender essas relações. Segundo ela (2007a, p. 135-136):

\begin{abstract}
[...] para que uma palavra faça sentido é preciso que ela já tenha sentido. Essa impressão do significar deriva do que se tem chamado "interdiscurso". Isto é, o domínio do "saber" discursivo, 0 da sua memória, aquele que sustenta 0 dizer numa estratificação de formulações já feitas mas "esquecidas" e que vão construindo uma história dos sentidos. Toda fala resulta assim de um efeito de sustentação no já-dito que, por sua vez, só funciona quando as vozes que se poderiam identificar em cada formulação particular se apagam e trazem 0 sentido para o regime do "anonimato" e da "universalidade". llusão de que o sentido nasce ali, não tem história.
\end{abstract}

A epidemia explosiva da dengue em 2002 - que constituiu um acontecimento significativo para a saúde pública - foi determinante para a mídia divulgar amplamente 0 fato (acontecimento discursivo), fazendo evocar na lembrança os sentidos da epidemia e caracterizando 0 interdiscurso na construção dos discursos sobre a doença nos anos seguintes. Com a confirmação dos registros de doentes e mortes nem quantidade acima do esperado, 0 ano de 2002 passou a ser considerado um marco para a imprensa não só a título de informação jornalística e histórica, mas também como acontecimento de referência da doença na construção do seu discurso. Retomando a memória interdiscursiva de Moirand (1999 apud, CHARAUDEAU; MAINGUENEAU, 2008), constatamos que as formulações midiáticas vão reconfigurando a memória, ao confrontar acontecimentos do passado e do presente na interpretação dos acontecimentos.

Em janeiro de 2002, quando a epidemia se configurou em Pernambuco com o aumento de casos acima da média esperada, a imprensa já tinha gravado na lembrança 0 evento epidêmico de 1997 no Recife, considerado "0 ano mais complicado na cidade":

Recife pode estar vivendo de fato a sua maior epidemia de dengue. 0 rápido avanço da doença nos dois últimos meses faz a Diretoria de Epidemiologia e Vigilância à Saúde do município pensar na possibilidade. 0 total de casos confirmados da forma clássica nesse período chega a 5.834 , conforme boletim divulgado ontem. Os números superam a soma de doentes dos dois anos anteriores e representam $69 \%$ dos registros feitos durante todo 0 ano de 1997, considerado o mais complicado, quando 8.374 pessoas tiveram 0 diagnóstico de dengue clássica confirmado. (JC. 843 pessoas infectadas em apenas um dia no Recife. 01/03/2002) 
Analisando o trecho, vemos que a comparação entre os anos é uma estratégia adotada pela imprensa para constituir sentido a respeito da dengue em 2002. Tendo como base 0 interdiscurso, ela vai entrelaçando os fatos do presente e do passado com relação às notificações para configurar novos significados. A partir do "rápido avanço da doença", o jornal declara a possibilidade de 2002 registrar a "maior epidemia de dengue", uma vez que os "números superam a soma de doentes dos dois anos anteriores [2001 e 2000] e representam $60 \%$ dos registros feitos durante todo o ano de 1997, considerado o mais complicado". Os exemplos a seguir mostram a importância dada à epidemia em diferentes momentos pós-2002:

(02)

De janeiro até ontem, foram registrados 112 casos de dengue na cidade, mas só um foi confirmado até o momento.

"Os números estão um pouco acima do que registramos nesse mesmo período do ano passado, mas o quadro é normal, muito distante da epidemia de 2002", esclarece Tereza Lyra, diretora de Vigilância à Saúde do Recife. (JC. Confirmada a primeira morte por leptospirose. 20/03/2004)

(03)

2006 está sendo considerado o segundo pior ano da epidemia no Brasil e em Pernambuco.
Só perde para 2002, quando morreram mais de 150 pessoas no País, 19 delas no Estado. (JC. Estado antecipa mobilização no segundo pior ano da epidemia. 17/11/2006)

Pelos dois trechos destacados, podemos verificar alguns dos elementos de memória sobre a epidemia de 2002 incorporados aos discursos posteriores sobre a dengue. Em 2004, o quadro da dengue se mostrava "muito distante da epidemia de 2002", enquanto que, em 2006, a epidemia, apesar de ser a segunda pior, "só perde para 2002". Jornalisticamente falando, o expediente de comparar situações epidemiológicas entre os anos se mostra valioso na definição de espaço do noticiário, ao dar a real dimensão do problema para 0 seu público.

Essa comparação não ocorre apenas na fala do enunciador (neste caso, o jornal), mas também nas citações dos entrevistados, 0 chamado discurso direto, ${ }^{5}$ que busca restituir as falas como forma de reforçar 0 argumento da matéria em questão, criando um efeito de verdade.

Destacamos a seguir o trecho de uma matéria de 2008 no qual o elemento pré-construído sobre a epidemia de 2002 foi incorporado à fala da gestora pública:

Segundo a secretária municipal de Saúde, Tereza Campos, 54 novos leitos serão abertos em

0 discurso direto é uma das formas mais comuns vistas nas matérias e reportagens do discurso relatado, juntamente com o discurso indireto, as aspas e a negação. Considerado um dos principais recursos empregados pelos repórteres na redação dos textos, o discurso relatado se caracteriza por ser abertamente citado e separado do discurso citante (MAINGUENEAU, 2002). 
três unidades conveniadas - Hospitais Maria Lucinda, Evangélico e Santo Amaro. "É importante ressaltar que essas medidas só serão tomadas se houver demanda que as justifique. Estamos monitorando os casos de dengue e por enquanto a situação é de alerta. Não chegamos ao limite máximo de casos, como ocorreu em 2002, por exemplo", afirmou Tereza Campos. (JC. Prefeitura pretende abrir postos nos fins de semana. 24/04/2008)

A referência à epidemia de 2002 é utilizada interdiscursivamente nos textos sempre que se pretende denotar 0 avanço ou o controle da dengue. No caso da citação destacada (exemplo 04), a secretária de saúde reconhece que "a situação é de alerta" em 2008, embora ressalte que Recife ainda não tenha chegado "ao limite máximo de casos, como ocorreu em 2002". Como dissemos, esquecer e lembrar estão diretamente ligados à memória e ao interdiscurso (ORLANDI, 2007b). Os acontecimentos novos também reformulam os discursos e a própria memória. Claro que o que chama mais atenção para a mídia ganha valor de destaque e, portanto, é passível de lembrança. E a epidemia da dengue de 2002, como evento de referência, ainda parece estar guardada tanto na memória coletiva das pessoas quanto na memória discursiva jornalística, apresentando uma relação marcadamente interdiscursiva nas matérias até então e sendo "evocada", sobretudo, nos contextos de maior risco.

A magnitude da dengue - que configurou a situação como a pior de todos os tempos em
Pernambuco e no Brasil - foi fundamental para analisar a atitude valorativa negativa que se consolidou por meio dos enunciados da imprensa nos anos posteriores, através da identificação da palavra "epidemia" na prática discursiva. Isso não vem de hoje e nem é "obra" da dengue apenas. As noções de medo e mal estão intimamente ligadas à produção de sentidos das doenças infecciosas (como a dengue), transmitidas por um agente biológico, que pode ser um vírus, uma bactéria ou um parasita.

Nessas enfermidades transmissíveis, em que não se visualiza 0 agente, mas em que se vê e sente concretamente 0 corpo doente, a materialização da epidemia no contexto da coletividade enfatiza a noção do mal no território geográfico se alastrando - seja na cidade, no estado, no país ou até mesmo no mundo - e espalhando o medo entre as pessoas. Em alguns casos, o risco potencial de morte, especialmente com o maior desenvolvimento nos últimos anos da forma hemorrágica entre os doentes, também se encontra bastante presente nas notícias. Na epidemia de 2002, 20 pessoas morreram, enquanto que, na epidemia de 2008, foram registrados 19 óbitos em Pernambuco. ${ }^{6}$ Para nós, entender essa ameaça é fundamental a fim de verificar o estado de alerta da mídia diante de aumento de casos e suspeitas de mortes. 


\section{Análise da narrativa jornalística sobre a dengue}

Para compreendermos as memórias criadas sobre dengue no campo jornalístico, analisamos também a produção da narrativa sob 0 viés discursivo. No Brasil, desde os anos 80 do século XX, a produção dessa narrativa vem corporificando discursivamente a dengue e tornando a experiência de adoecer pela moléstia cada vez mais comum para a população. Em Pernambuco, bem como no restante do país, acreditamos que essa experiência ganhou fôlego, a partir dos anos 2000, dada a dimensão das epidemias registradas, demandando uma maior produção de matérias, reportagens e notas, em alguns períodos quase que diárias.

Charaudeau (2009) diz que 0 discurso apresenta quatro modos distintos e interligados de organização. São eles: 0 enunciativo (posiciona o locutor em relação ao interlocutor através dos enunciados constituídos), o descritivo (identifica e qualifica os seres de forma objetiva e subjetiva), o narrativo (constrói um relato do acontecido com base na sucessão de ações ao longo do tempo) e 0 argumentativo (expõe e prova casualidades com vistas a influenciar 0 interlocutor). Textos que materializam a encenação do ato de comunicação, os relatos da imprensa combinam o modo descritivo e o narrativo. Ambos são regidos pelo modo enunciativo, uma espécie de forma-base para a produção discursiva de qualquer gênero.
Nas narrativas jornalísticas, o modo enunciativo produz um "apagamento" do repórter no ato da enunciação e não demanda a presença do interlocutor (situação monologal). Nesse modo, 0 comportamento delocutivo caracteriza a produção dos enunciados, com predominância das marcas da $3^{\mathrm{a}}$ pessoa do singular nos textos, criando um efeito de objetividade e distanciamento do autor. 0 jornalista seria não apenas uma testemunha ocular dos fatos, mas também uma testemunha das testemunhas, ao retomar discursos de outrem na sua própria enunciação, neste caso, por meio do discurso relatado. Na imprensa, a finalidade do comportamento delocutivo é mostrar que há sempre uma fonte que fala e como ela fala, conferindo credibilidade ao relato. Ao públicoleitor, segundo Pereira Junior (2009, p. 151, grifo nosso), cabe aceitar essa "realidade traduzida" em texto por meio de um pacto de confiança estabelecido previamente com o jornalismo. "Ao comprar o periódico de sua preferência, todo leitor tacitamente confia que o repórter seja sua testemunha dos fatos. 0 jornalista vê a 'realidade' em seu lugar e deverá traduzir tudo com fidelidade".

No relato jornalístico, o modo descritivo funciona com o propósito de nomear os seres envolvidos na cobertura dos acontecimentos (finalidade de informar), de localizar-situar esses seres no tempo e no espaço (finalidade de explicar) e de qualificá-los (finalidade de contar). De acordo com Charaudeau (2009, p. 116, grifo do autor), esse modo descritivo "serve essencialmente para 
construir uma imagem atemporal do mundo.

Realmente, a partir do momento em que os seres do mundo são nomeados, localizados e qualificados, é como se eles fossem impressos numa película para sempre". Na visão dele, embora não seja totalmente dependente, o modo descritivo ganha sentido em função dos outros modos de organização, produzindo no discurso das mídias efeitos de saber (prova de veracidade) e de realidade.

Já o modo de organização narrativo concebe o discurso através da construção de ações encadeadas (lógica narrativa) e da criação de um universo contado (encenação narrativa). Nessa dupla articulação, coabitam a organização do mundo referencial e a fixação de um contrato entre o narrador e o destinatário. Na lógica narrativa, a construção se dá por meio de três componentes:

a) os actantes (ligados aos papéis narrativos e à ação em si), b) os processos e funções narrativas (orientam a ação, unindo os actantes entre eles) e c) as sequências (integram processos e actantes por princípios de coerência, intencionalidade, encadeamento e localização). A encenação narrativa, por sua vez, articula dois espaços de significação entre o narrador e o leitor: um externo (encontro do autor com o leitor "real" - seres de identidade social) e outro interno (encontro do narrador com o leitor-destinatário - seres de identidade discursiva, que correspondem ao enunciador e ao destinatário).

Pensando no discurso da informação, matériaprima das mídias, o jornalista atua como 0 responsável pela narrativa do fato, convertendo-se num autor-historiador por contar "a posteriori acontecimentos que se produziram, após haver reunido um certo número de documentos e testemunhos" (CHARAUDEAU, 2009, p. 192, grifo do autor). A afirmação converge para Pereira Junior (2009, p. 30), que compara o jornalista a um intérprete. "Não um intérprete qualquer. Ele trabalha sobre um substrato de vestígios, testemunhos e elementos, constrói um contexto para o fato por ele isolado".

Para nós, o modo narrativo nos interessa mais por ser constitutivo do campo jornalístico, sendo utilizado pelos repórteres para contar os fatos que pertencem a um passado recente, na maioria das vezes, relativo ao ontem. Por meio das narrativas, a imprensa vai construindo o enredo da dengue, tendo em vista a evolução da doença. Tomando emprestado o pensamento de Fausto Neto (1999), que estudou a construção de sentidos sobre a Aids nos principais periódicos brasileiros entre as décadas de 80 e 90, a partir dos modos de dizer da imprensa, a dengue vai tomando corpo no espaço social e nas páginas do jornal.

Em geral, a notificação dos casos encadeia os fatos relativos à dengue, estruturando a narrativa jornalística. Para Charaudeau (2009, p. 166, grifo do autor), essa ordenação integra a sequência narrativa, concebida na lógica de organização do discurso como "uma sucessão de acontecimentos ligados por uma relação de solidariedade tal que cada um pressupõe os outros numa estrutura 
que se deve imaginar intemporal" sob princípios de coerência, intencionalidade, encadeamento e localização. Pensando nessas sequências narrativas, vemos a ênfase da aproximação da ameaça que o descontrole da doença representa como outro fenômeno discursivo que atrela 0 encadeamento de ações e sentidos face à instalação da epidemia da dengue. Visível nos textos, esse sentimento de proximidade do perigo não apenas condiciona os medos sanitários na atualidade, como também determina a relevância da notícia no espaço do periódico (OGRIZEK; GUILLERY; MIRABAUD, 1996).

As manchetes a seguir ilustram essa noção de chegada da doença (Figura 1):

A partir de um dizer notificador de casos, bem como o registro de mortes, essa ideia de aproximação da doença confirma a influência decisiva da notificação sobre o regime enunciativo do jornal e a estrutura da narrativa. A ocorrência de uma epidemia reconfigura a memória discursiva e determina a extensão e 0 volume da narrativa. Consideradas jornalisticamente "anúncios do texto" (LAGE, 2008), as manchetes ressaltam 0 agravamento da situação face a uma potencial ameaça, como forma de o jornal "captar" o seu público.

Nessa construção, o jornal lança mão de alguns verbos característicos, como crescer, para denotar 0 aumento progressivo da quantidade de registros da doença (neste caso, 200\% em quase uma semana), alarmar, que significa "pôr(-se) em alarme; assustar(-se)" (HOUAISS, 2009, p. 82), e espalhar, a fim de noticiar a disseminação da dengue pelo território (no exemplo destacado, o interior de Pernambuco). Além disso, outros termos são comuns. Numa das capas, o jornal utiliza o "em alerta" para informar que 0 Estado está vigilante com a morte ocorrida. Mais que

Figura 1 - Manchetes de capa publicadas pelo Jornal do Commercio durante epidemias de dengue

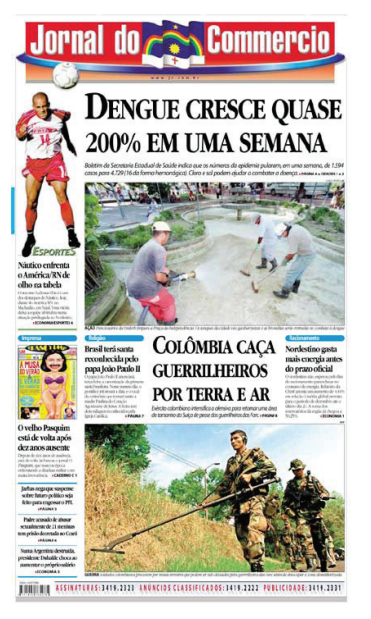

Edição de 23 de fev. 2002

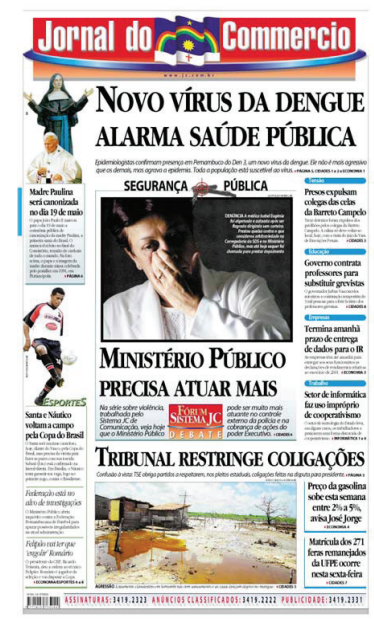

Edição de 27 de fev. 2002

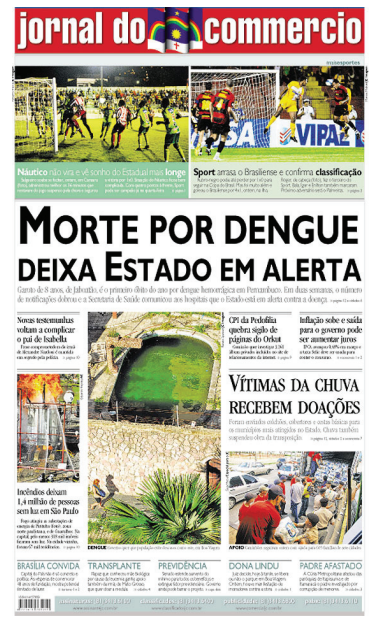

Edição de 10 de abr. 2008

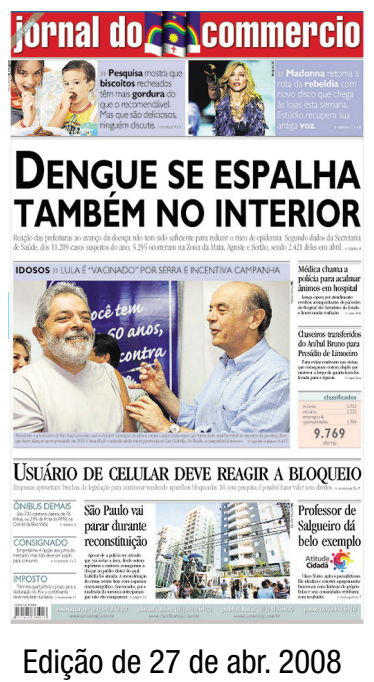


configurar a situação epidemiológica, o vocabulário utilizado contribui para consolidar a noção de risco da dengue.

A epidemia se torna, então, o fio condutor na narrativa sobre a dengue, que puxa a história em direção ao futuro, "permitindo que o leitor ou 0 ouvinte vivencie imaginariamente os acontecimentos relatados" (SODRÉ, 2009, p. 205). A orientação da narrativa sintetiza a luta contra uma doença potencialmente mortal (seja a febre hemorrágica ou a dengue clássica com complicações, que também pode matar) acometendo a todos, independentemente de classe social. Esse esquema funciona mediante a uma não-aceitação da morte por parte do poder público, dos cidadãos e dos demais segmentos da sociedade, por representar a imprevisibilidade possível no contexto das epidemias. Sendo assim, vemos que a narrativa sobre a epidemia demanda outras narrativas que combatam o "mal" sanitário infeccioso, sobretudo quando são promovidas iniciativas para barrar o avanço da doença.

Nesse sentido, as iniciativas para controlar a dengue, principalmente do poder público, costumam ter espaço privilegiado no jornal logo após a constatação do aumento demasiado de casos e o registro das primeiras mortes, aparecendo na sequência da instalação do evento epidêmico. Evidentemente que esse tipo de narrativa não ocorre apenas durante as epidemias, no entanto, ganha fôlego em momentos em que a doença apresenta certo descontrole. Nos quatro anos de nossa pesquisa, as publicações sobre combate somaram $37,2 \%$ dos 291 textos veiculados. Destacamos alguns exemplos de títulos de matérias que enfatizam essa noção de combate e recuperam o discurso de guerra por meio do interdiscurso (Quadro 1):

Quadro 1 - A militarização na titulação das manchetes - Jornal do Commercio, 2002, 2004, 2006 e 2008

\begin{tabular}{|c|c|}
\hline $22 / 02 / 2002$ & EPIDEMIA: PM reforça combate à dengue \\
\hline $01 / 03 / 2002$ & EPIDEMIA: Olinda capacitará soldados do Exército para erradicar focos \\
\hline $02 / 03 / 2002$ & EPIDEMIA: Estudantes da UFPE formam brigada para monitorar o campus \\
\hline $09 / 03 / 2002$ & EPIDEMIA: Construtoras entram na luta contra doença \\
\hline $27 / 11 / 2004$ & SAÚDE PÚBLICA: PCR intensifica ações contra dengue \\
\hline $01 / 07 / 2006$ & SAÚDE: Recife faz mobilização contra surto de dengue \\
\hline $30 / 12 / 2006$ & Erva é arma contra mosquito da dengue \\
\hline $02 / 05 / 2008$ & LUTA CONTRA A DENGUE: Passeata na Zona Norte alerta para a prevenção \\
\hline $19 / 05 / 2008$ & MEGAOPERAÇÃo: Recife se une contra a dengue \\
\hline $20 / 05 / 2008$ & COMBATE À DENGUE: Ambulantes são alvo de ação \\
\hline $01 / 06 / 2008$ & GUERRA AO MOSQUITO: Arquitetura é obstáculo para o combate à dengue \\
\hline $24 / 10 / 2008$ & PLANO DE AÇÃO: Estado quer agilizar registros de dengue \\
\hline
\end{tabular}


Vemos que as manchetes resgatam o discurso de guerra, enfatizando a adoção de táticas militares no combate à dengue nos seus enunciados. Dessa forma, o reforço se torna necessário no combate à dengue, seja com a inserção de soldados do Exército (que representa a militarização simbólica das ações de controle da dengue) para erradicar focos, seja com o apoio de universitário na formação de uma brigada para monitorar 0 campus. 0 uso de outros termos tais como luta, ação, intensificar, mobilização, arma, alerta, alvo e obstáculo nos exemplos selecionados também evidencia o discurso de guerra nos enunciados jornalísticos.

Observando o conjunto de títulos do quadro 1, notamos que 2008 foi 0 ano em que mais se enfatizou o discurso de guerra. Esse "fenômeno" discursivo foi alimentado pelas inúmeras ações promovidas pelos governos e a sociedade civil, a ponto de o jornal inserir o combate na sua agenda editorial, a partir da utilização de um leque maior de termos comuns à guerra nas manchetes, como luta contra a dengue, megaoperação, combate à dengue, guerra ao mosquito e plano de ação, a exemplo do que havia ocorrido com a palavra em 2002 no regime de titulação das matérias. Segundo Fausto Neto (1999, p. 62), o uso de operadores na edição dos títulos do jornal cria uma subagenda sobre a temática em questão dentro da agenda cotidiana definida pelo veículo de comunicação. "Através dele, o jornal anuncia uma espécie de ‘encontro marcado' com o leitor”. Assim, a guerra ocupou um espaço privilegiado e visível ao públicoleitor, conferindo novos sentidos às manchetes.
Em relação às metáforas militares, Sontag (2002) lembra que elas começaram a ser usadas no mundo no campo médico, no fim do século XIX, com a identificação das bactérias como agentes causadores de doenças. Na época, referia-se à "invasão" ou à "infiltração" para descrever a ação dos germes no organismo. Posteriormente, os termos metaforizados ganharam "corpo" a partir das campanhas de conscientização sobre a sífilis que foram realizadas durante a Primeira Guerra (1914-1918) e, depois, nas de esclarecimento a respeito da tuberculose. No Brasil, o uso dessas metáforas nos remete às primeiras campanhas de vacinação, a exemplo da estratégia empreendida no início do século XX para conter a epidemia de varíola (UJVARI, 2003). Os conceitos de contenção e vigilância, de inspiração militar, surgiram depois da Primeira Guerra, sendo utilizados pela saúde pública, que adotou a visão do "inimigo" para combater os problemas sanitários da época. Assim, os programas de vacinação e as campanhas de saúde foram fortemente influenciados por esse modelo para combater às doenças endêmicas, ameaça ao desenvolvimento dos centros urbanos.

Levar em conta essa historicidade é fundamental para tentar entender os sentidos atuais no "jogo complexo da discursividade", como diz Orlandi (2007a). Ainda hoje as noções de inimigo e guerra são elementos muito presentes nos discursos da saúde pública. Com o tempo, essa noção de guerra acabou sendo assimilada e reforçada pela imprensa na construção do seu discurso. 0 próprio mosquito transmissor (Aedes aegypti), 
conhecido popularmente como muriçoca, é retratado como um inimigo, assim como os vírus, a epidemia e a própria doença. Todos, em especial o mosquito (único ser visível dentre os quatro "entes" ligados à moléstia), são encarados como 0 adversário contra 0 qual se deve eliminar. Na lógica da narrativa, os quatro formam um dos actantes principais - cada qual a seu modo, a depender do tipo de abordagem do noticiário -, encarnando a noção do "mal", mesmo não sendo humano.

Embora tenhamos a tendência de imaginar que actante é o mesmo que personagem na narrativa jornalística existe uma diferença. Segundo Charaudeau (2009), o actante é uma forma não qualificada que assume uma substância semântica conforme o papel que assume na ação (forma qualificada). Ao fazer uma distinção entre actante e personagem, fica mais fácil compreendermos o jogo de correspondências existente entre cada um deles. Para o linguista, significa dizer que "[...] um actante, tendo um certo papel narrativo, pode ser ocupado por diferentes tipos de personagens, seja sucessivamente, seja alternativamente, seja simultaneamente". Por outro lado, um "[...] personagem pode desempenhar muitos papéis narrativos e ocupar o lugar de actantes diferentes, no desenrolar da mesma história" (CHARAUDEAU, 2009, p. 162).

Como cada texto engendra uma ação diferenciada, esses actantes mudam conforme 0 contexto. Além do mosquito / dos vírus / da epidemia / da própria dengue, o poder público, o cidadão e os doentes / ex-doentes compõem os demais actantes de base, devido à importância não apenas no "enredo", como também na relação deles dentro do espaço público em que as epidemias são uma realidade. Ao lado dos pólos de ação, gravitam actantes satélites que circundam a trama (profissionais de saúde e pesquisadores), complementando a lógica narrativa. 0s exemplos 05 e 06 evidenciam a dengue como agente agressora:

0 vírus 3 da dengue, isolado há 13 dias no sangue de dois moradores do Recife e de um terceiro de Nazaré da Mata, já alcançou habitantes de outras cidades pernambucanas. (JC. Novo vírus da dengue atinge mais três cidades. 10/03/2002)

0 objetivo, segundo a Secretaria Municipal de Saúde, é mobilizar a comunidade para evitar a formação de novos focos do mosquito Aedes aegypti e barrar a transmissão da doença, que avança desde maio. (JC. Programação marca dia municipal de combate à doença. 28/07/2006)

A noção de adversário é vista nos enunciados que enfatizam a dengue se adiantando sobre o território ("vírus 3 da dengue já alcançou habitantes de outras cidades pernambucanas" / "doença avança desde maio"). Já no exemplo 07, o mosquito aparece como actante que representa a dengue. Num texto em que se pretende incentivar 0 engajamento na luta contra a enfermidade, o Aedes aegypti é considerado um ser "terrível e temido": 
(07)

A caça em alta exige instrumentos e táticas simples: disposição, olhar atento, discurso convincente, criatividade e consciência social. E é isso que gente de todas as idades anda explorando de si para reforçar o exército contra o Aedes aegypti, o terrível e temido mosquito da dengue. (ALMEIDA. Caça ao mosquito: Anônimos entram na luta. 04/05/2008)

Dentro dessa correlação entre actante e personagem, o poder público assume o papel de vítima que reage contra a dengue. Muitas vezes, é visto como 0 agente que empreende ações para acabar com o mosquito. Sendo benfeitor, também conclama a população a ser sua aliada, denotando a presença do discurso da corresponsabilidade na sua fala para conscientizá-la sobre o problema, dividindo funções originariamente suas. 0 exemplo 08 indica isso:

0 secretário de Saúde [Guilherme Robalinho] lembrou, ainda, da importância de toda a sociedade participar da luta para acabar com o mosquito da dengue. [...] "Não temos vacina, nem tratamento para combater a dengue. Por isso, a solução é evitar que as larvas do mosquito se desenvolvam", afirmou. (JC. Doença já atingiu 12,4 mil pessoas em Pernambuco. 08/03/2002)

Diante das dificuldades em se controlar a dengue, a importância do engajamento da sociedade é reforçada nos discursos dos gestores, a exemplo da fala do secretário de Saúde ("0 secretário de Saúde lembrou ainda da importância de toda a sociedade participar da luta para acabar com 0 mosquito"). Em outros momentos, o gestor culpa o cidadão pela falta de apoio, dando a entender que ele também era responsável pelo descontrole (exemplo 09):

\begin{abstract}
“As pessoas estão acomodadas. Não incorporaram a responsabilidade que também é delas", lembra [Claudenice Pontes, da Vigilância Ambiental.]. (JC. Foco em casa de veraneio preocupa. 26/04/2008)
\end{abstract}

Analisando os enunciados, percebemos que, com o passar do tempo, houve um atrelamento do discurso da corresponsabilidade à culpabilização do cidadão. Isso ficou mais evidente, em 2008, na fase de pico da doença, quando o engajamento, a corresponsabilidade e as críticas ao poder público estiveram bastante próximos na produção do noticiário. Em alguns momentos, o próprio jornal também se autorizou a opinar a respeito do papel do cidadão na luta contra a dengue, assumindo uma posição crítica, com o intuito de incentivar nele novos hábitos a partir de um dizer opinativo, como é possível ver no exemplo 10:

Combater apenas os grandes focos de proliferação do mosquito Aedes aegypti não é suficiente para controlar a multiplicação das larvas. É preciso modificar hábitos de moradores desatenciosos que contribuem de alguma forma para 0 agravamento do surto da dengue. (JC. Mutirão tenta mudar hábitos da população. 01/05/2008) 
A dificuldade do Estado em garantir a proteção do indivíduo com relação à dengue revela 0 poder público como um "herói falho", que não é capaz de dar conta do seu dever de controlar a proliferação da doença no território em que administra. Por isso mesmo, o discurso da corresponsabilidade parece ser importante nos dias de hoje, levando o cidadão a pensar na sua proteção e na da comunidade em que vive, às vezes numa perspectiva individualista. Essa ideia do "herói falho" costuma ser visto nos discursos da população e da imprensa, que denunciam 0 descaso e a falta de comprometimento no controle. As críticas são mais contundentes nas epidemias, quando a doença se torna alvo das atenções (exemplos 11 e 12): 0s moradores denunciam que há mais de
seis meses a comunidade não recebe a
visita dos agentes do programa de combate à
dengue. (JC. Número de mortos sobe para 5 .
20/04/2002)

As ações de vigilância ambiental foram comprometidas entre 2004 e 2005, na transição dos prefeitos. Em parte das cidades houve desmobilização de equipes responsáveis pela identificação e tratamento dos focos do mosquito. (JC. Grande Recife tem $35 \%$ dos casos de dengue. 28/07/2006)

Em meio ao risco, a busca por "responsáveis" pelo surgimento ou a falta de controle da ameaça perpassa as narrativas jornalísticas. É inerente ao ser humano procurar explicações para os problemas observados no seu cotidiano. "Encontrar as causas de um mal é recriar um quadro tranqüilizador, reconstituir uma coerência da qual sairá logicamente a indicação dos remédios", reconhece Delumeau (2009, p. 201), ao refletir acerca 0 impacto causado outrora pela peste. Claro que existem diferenças entre 0 passado e o presente, mas a busca pelas causas de um "mal" sanitário permanece. Nas narrativas jornalísticas, essa procura ganha um sentido maior, uma vez que 0 ato de contar é inerente ao homem e tem 0 objetivo de encontrar respostas à verdade dos fatos e do nosso próprio ser.

$\mathrm{Na}$ imprensa, as tensões e contradições estariam expressas através do embate das vozes que compõem a narrativa na busca por essa verdade que não se revela espontaneamente, compromisso, aliás, firmado pelo próprio jornalismo com o seu público na constituição do seu campo. "0 desafio do repórter (no cenário complexo, tentacular, da desordenada torrente de acontecimentos que forma a vida contemporânea) é encontrar evidências soterradas em camadas de versões, procurar certezas em situações de incerteza" (PEREIRA JUNIOR, 2009, p. 71). Por isso, os problemas relativos ao controle da dengue sejam desvelados mais facilmente nos momentos de descontrole.

Dentro desse hibridismo das narrativas sobre a dengue, 0 cidadão assume 0 papel de oponente do governo (exemplo 11, já visto anteriormente), 
embora também possa aparecer como seu aliado, quando elogia as ações desenvolvidas pelo poder público (exemplo 13):

\begin{abstract}
Maria do Bom Parto do Nascimento, residente na $2^{\mathrm{a}}$ Travessa da Amizade, em Santo Amaro, gostou da ação anunciada pela Secretaria de Saúde. "A idéia é ótima e espero receber uma caixa d'água", diz a dona de casa, que armazena água em baldes e botijões. Ela tem medo que sua neta de um ano tenha a doença. (JC. Recife vai distribuir caixas d'água. 30/01/2002)
\end{abstract}

Além disso, o cidadão aparece como aliado quando reconhece a necessidade de tomar uma atitude para evitar o aparecimento de focos do mosquito na comunidade (exemplo 14):

Segundo José Soares [morador do Alto Nossa Senhora de Fátima, no Vasco da Gama, Zona Norte do Recife], vivem na comunidade cerca de oito mil pessoas. "Os agentes de saúde não dão conta de orientar todos os moradores, pois há muitas casas no Alto. A gente tem que ajudar", afirmou o militar. (JC. Passeata na Zona Norte alerta para a prevenção. 02/05/2008)

Pelo estudo, constatamos que 0 cidadão, 0 paciente e ex-paciente com dengue costumam ser "autorizados" a falar com mais frequência nos momentos de maior vulnerabilidade da dengue. Só nesses períodos, os dois personagens parecem "ter o que dizer", já que existe uma epidemia instalada ou um risco de epidemia e eles são os principais afetados. Caso contrário, saem da cena narrativa, permanecendo apenas a saúde pública informando sobre a situação da moléstia e, em alguns casos, algum pesquisador divulgando seu estudo. Em 2004 e 2006, o doente desapareceu por completo da cobertura.

A nosso ver, essa "voz limitada" do cidadão e dos pacientes e a inserção condicionada dos demais actantes da narrativa reeditam sentidos praticamente idênticos em cima do mesmo. Para nós, essas limitações e condicionamentos indicam que os veículos de comunicação costumam jogar mais com a paráfrase que com a polissemia na produção de significados sobre a dengue nas notícias. Para Orlandi (2007b), os sujeitos e sentidos se constituem na relação tensa entre os jogos parafrásticos e polissêmicos, condição de possibilidade da linguagem para o mesmo (a produtividade, a estabilização e a memória) e 0 diferente (a criatividade, a ruptura e o equívoco). A nosso ver, a polissemia geralmente passa ao largo da produção da notícia propriamente dita, dando a entender que a realidade da dengue é sempre a mesma na imprensa, a depender do contexto da doença. Pelo menos, é o que parece ser.

\section{Conclusão}

É inegável a relevância da dengue para o campo jornalístico. Possivelmente nenhuma outra doença infecciosa tenha tido tanto espaço nos últimos anos no noticiário quanto ela, devido à ocorrência cíclica de epidemias e o risco de morte pela forma hemorrágica, que representa uma ameaça 
cada vez maior. Com exceção da gripe suína, que resgatou no fim desta primeira década do século XXI a noção de "mal planetário" em decorrência da pandemia declarada, a dengue encontra sempre lugar cativo nas páginas dos jornais, tornando a experiência da doença mais comum para a população pela ampla divulgação do assunto.

Assumindo o posto de Nêmesis Brasileira (SILVA; ANGERAMI, 2008), a dengue já se configura na doença símbolo da história pública, assim como foi com a febre amarela no início do século XX, em função do impacto das epidemias urbanas. Deusa que personifica a vingança na mitologia grega, a Nêmesis representa na atualidade 0 extremo oposto de alguém, mas ao mesmo tempo muito semelhante a si, razão pela qual faz com que a dengue seja vista simbolicamente como um dos maiores inimigos da saúde pública brasileira, criando metaforicamente um embate entre os dois. 0 volume do arquivo constituído pelos textos publicados pelo Jornal do Commercio ao longo dos quatro anos do nosso estudo comprova a força da dengue no agendamento da imprensa.

Interdiscursivamente, a epidemia estabelece uma relação entre 0 passado e 0 presente quando se pretende denotar 0 avanço ou não da moléstia. As marcas de reconfiguração da memória indicam a presença do interdiscurso na produção de sentidos. Embora cada doença infecciosa tenha suas características particulares, todas elas resgatam de alguma forma a memória das antigas pestes na constituição de sentidos. Sendo assim, noções contidas nas matérias atuais de medo, mal, morte e risco estão ligadas às moléstias que fizeram história no passado. Através do estudo, verificamos que 0 espaço concedido à dengue costuma ser maior e com destaque nos momentos de desequilíbrio. Constatamos ainda que 0 contexto da dengue dita a cobertura da mídia, definindo o que "deve" ser dito, bem como quem "pode" falar.

Diante da inviabilidade de erradicação do mosquito no mundo, a Organização Mundial de Saúde (OMS) definiu, desde 1995, a participação da comunidade envolvida e de todos os setores da sociedade como um dos elementos básicos para prevenir e controlar a dengue, de acordo com Guzmán, Kourí e García (2006). Ao avaliar o tratamento dado pela imprensa pernambucana à dengue, acreditamos que a academia também possa se inserir nesse processo, promovendo uma discussão sobre 0 assunto e lançando luzes no repensar as estratégias de controle e prevenção da dengue no âmbito da comunicação.

\section{Referências}

843 PESSOAS infectadas em apenas um dia no Recife. Jornal do Commercio, Recife, ano 84, n. 60, 1 mar. 2002. Caderno Cidades

ALMEIDA, V. Caça ao mosquito: Anônimos entram na luta. Jornal do Commercio, Recife, ano 90, n. 125, 4 mai. 2008.

Novo vírus da dengue atinge mais três cidades. Jornal do Commercio, Recife, ano 84, n. 69, 10 mar. 2002. 
ALVES, C. Arquitetura é obstáculo para o combate à dengue. Jornal do Commercio, Recife, ano 90, n. 153, 1 jun. 2008.

AMBULANTES são alvo de ação. Jornal do Commercio, Recife, ano 90, n. 141, 20 mai. 2008. Caderno Cidades.

BARATA, Rita de Cássia Barradas. Saúde e direito à informação. Cadernos de Saúde Pública. Rio de Janeiro, v. 6, n. 4, out./dez. 1990.

CHARAUDEAU, Patrick. Discurso das mídias. São Paulo: Contexto, 2006.

Linguagem e discurso: modos de organização. São Paulo: Contexto, 2009.

; MAINGUENEAU, D. Dicionário de Análise do Discurso. 2.ed., São Paulo: Contexto, 2008.

CONFIRMADA a primeira morte por leptospirose. Jornal do Commercio, Recife, ano 86, n. 80, 20 mar. 2004. Caderno Cidades.

CONSTRUTORAS entram na luta contra doença. Jornal do Commercio, Recife, ano 84, n. 68, 9 mar. 2002. Caderno Cidades.

COURTINE, Jean-Jacques. Análise do discurso político: o discurso comunista endereçado aos cristãos. São Carlos: Ed. da UFSCar, 2009.

DELUMEAU, Jean. História do medo no Ocidente: uma cidade sitiada. São Paulo: Companhia das Letras, 2009.

DOENÇA já atingiu 12,4 mil pessoas em Pernambuco. Jornal do Commercio, Recife, ano 84, n. 67, 8 mar. 2002. Caderno Cidades.

DONALÍSIO, Maria Rita. 0 dengue no espaço

habitado. São Paulo: Hucitec, 1999.

ERVA é arma contra mosquito da dengue. Jornal do Commercio, Recife, ano 88, n. 364, 30 dez. 2006. Caderno Ciência \& Meio Ambiente.
ESTAD0 antecipa mobilização no segundo pior ano da epidemia. Jornal do Commercio, Recife, ano 88, n. 322, 17 nov. 2006. Caderno Cidades.

ESTAD0 quer agilizar registros de dengue. Jornal do Commercio, Recife, ano 90, n. 298, 24 out. 2008.

ESTUDANTES da UFPE formam brigada para monitorar o campus. Jornal do Commercio, Recife, ano 84, n. 61, 2 mar. 2002.

FAUSTO NETO, Antônio. Comunicação e mídia impressa: estudo sobre a Aids. São Paulo: Hacker, 1999.

F0C0 em casa de veraneio preocupa. Jornal do Commercio, Recife, ano 90, n. 117, 26 abr. 2008. Caderno Cidades.

FOUCAULT, Michel. A arqueologia do saber. 7. ed. Rio de Janeiro: Forense, 2007.

. 0 nascimento da clínica. 6. ed. Rio de Janeiro: Forense, 2006

GRANDE RECIFE tem 35\% dos casos de dengue. Jornal do Commercio, Recife, ano 88, n. 209, 28 jul. 2006. Caderno Cidades.

GUZMÁN, M. G.; KOURÍ, G. G.; GARCÍA, G. El dengue y el dengue hemorrágico: prioridades de investigación. Revista Panamericana de Salud Pública.

Washignton, v. 19, n. 3, p. 204-215, mar. 2006

HOUAISS, Antônio. Dicionário Houaiss da língua portuguesa. Rio de Janeiro: Objetiva, 2009.

JORNAL DO COMMERCIO. Jornal Diário. Recife, ano 84, n. 54, 23 fev. 2002.

Jornal Diário. Recife, ano 84, n. 58, 27 fev. 2002.

Jornal Diário. Recife, ano 90, n. 101, 10 abr. 2008.

Jornal Diário. Recife, ano 90, n. 118, 27 abr. 2008. 
LAGE, Nilson. A reportagem: teoria e técnica de entrevista e pesquisa jornalística. 7. ed. Rio de Janeiro: Record, 2008.

MAINGUENEAU, Dominique. Análise de textos de comunicação. São Paulo: Cortez, 2002.

MOIRAND, S. Les índices dialogiques de contextualisation dans l apresse ordinaire. Cahiers de praxématique, Université de Montpellier 3, n. 33, p. 145-184, 1999.

MUTIRÃO tenta mudar hábitos da população. Jornal do Commercio, Recife, ano 90, n. 122, 1 mai. 2008. Caderno Cidades.

NÚMERO de mortos sobe para 5. Jornal do

Commercio, Recife, ano 84, n. 110, 20 abr. 2002.

Caderno Cidades.

OGRIZEK, M; GUILLERY, J. M.; MIRABAUD, C. Que sais-je? La communication médicale. Paris: Presses Universitaires de France, 1996.

OLINDA capacitará soldados do Exército para erradicar focos. Jornal do Commercio, Recife, ano 84, n. 60, 1 mar. 2002. Caderno Cidades.

ORLANDI, Eni Puccinelli. As formas do silêncio: no movimento dos sentidos. 6. ed., Campinas: Editora da Unicamp, 2007a.

Análise de discurso: princípios e

procedimentos. 7. ed. Campinas: Pontes, 2007b.

PASSEATA na Zona Norte alerta para a prevenção. Jornal do Commercio, Recife, ano 90, n. 123, 2 mai. 2008. Caderno Cidades.

PCR intensifica ações contra dengue. Jornal do Commercio, Recife, ano 86, n. 331, 27 nov. 2004. Caderno Cidades.

PÊCHEUX, Michel. 0 discurso: estrutura ou acontecimento. 5. ed. Campinas, SP: Pontes, 2008. Papel da Memória. In: ACHARD, P. et al. Papel
PEREIRA JUNIOR, L. C. A apuração da notícia: métodos de investigação na imprensa. 2. ed. Petrópolis, RJ: Vozes, 2009.

PM reforça combate à dengue. Jornal do Commercio, Recife, ano 84, n. 53, 22 fev. 2002. Caderno Cidades.

PREFEITURA pretende abrir postos nos fins de semana. Jornal do Commercio, Recife, ano 90, n. 115, 24 abr. 2008. Caderno Cidades.

PROGRAMAÇÃO marca dia municipal de combate à doença. Recife, ano 88, n. 240, 28 jul. 2006.

RECIFE faz mobilização contra surto de dengue.

Jornal do Commercio, Recife, ano 86, n. 182, 1 jul. 2006. Caderno Cidades.

RECIFE se une contra a dengue. Jornal do

Commercio, Recife, ano 90, n. 215, 2 ago. 2006.

Caderno Cidades.

RECIFE vai distribuir caixas d'água. Jornal do Commercio, Recife, ano 84, n. 30, 30 jan. 2002. Caderno Cidades.

RIBEIR0, Ana Paula Goulart. A mídia e o lugar da história. In: HERSCHMANN, Micael; PEREIRA, Carlos Alberto. (Org.). Mídia, memória e celebridades. 2. ed. Rio de Janeiro: E-Papers, 2005. p. 105-129.

ROUQUAYROL, Maria Zélia; ALMEIDA FILHO, Naomar (Org.). Epidemiologia e Saúde. 6. ed. Rio de Janeiro: MEDSI, 2003.

SILVA, Luiz Jacinto; ANGERAMI, Rodrigo Nogueira. Viroses emergentes no Brasil. Rio de Janeiro: Fiocruz, 2008

SODRÉ, Muniz. A narração do fato: notas para uma teoria do acontecimento. Petrópolis: Vozes, 2009.

SONTAG, Susan. A doença como metáfora. Rio de Janeiro: Graal, 2002.

Aids e suas metáforas. São Paulo:

Companhia das Letras, 1989. 
SOUTO MAIOR, Mário. A morte na boca do povo. Rio de Janeiro: Livraria São José, 1974.

UVJARI, Stefan Cunha. A história e suas epidemias: a convivência do homem com os microorganismos. Rio de Janeiro: SENAC; São Paulo: SENAC, 2003. 


\section{Epidemic and memory in the journalistic discourse about dengue fever}

\section{Summary}

This article presents the results of the dissertation Epidemic and memory: journalistic narratives in the discursive construction about dengue fever. Concluded at the Universidade Federal de Pernambuco (UFPE) in 2010, the survey aimed to evaluate the meanings produced by the press of Pernambuco about dengue fever, a disease that has affected more Brazilian people. Taking as its starting point the explosive epidemic of 2002 , we have selected 291 texts published by the Jornal do Commercio in $2002,2004,2006$ and 2008. We seek to identify the role of discursive memory and the presence of interdiscourse as well as deepen the analysis of the journalistic narrative. We have verified that the news is made based on ancient notions as fear, evil, death, risk and epidemic. In addition, the narrative structure and the insertion of the actors who talk about dengue fever are influenced according to the context of illness.

\section{Keywords}

Dengue Fever. Discursive Memory. Epidemic. Interdiscourse. Journalistic Narrative

\section{Epidemia y memoria en el discurso periodístico sobre el dengue}

\section{Resumen}

Este artículo presenta los resultados de la disertación Epidemia y memoria: los relatos periodísticos sobre la construcción discursiva del dengue. Concluída en la Universidade Federal de Pernambuco (UFPE) en 2010, la investigación tuvo el objetivo de evaluar los sentidos producidos por la prensa de Pernambuco sobre el dengue, una enfermedad que afecta más los brasileños. Tomando como punto de partida la epidemia explosiva de 2002, seleccionamos los 291 textos publicados por el Jornal do Commercio en 2002, 2004, 2006 y 2008 acerca de la molestia. En ellos se buscó identificar el papel de la memoria discursiva y la presencia de interdiscurso, así como profundizar el análisis de la narrativa periodística. Constatamos que la noticia se basa en nociones seculares de temor, mal, muerte, riesgo y epidemia. Además, la estructura narrativa y la inserción de los actores que hablan sobre el dengue está condicionada al contexto de la enfermedad.

\section{Palabras claves}

Dengue. Epidemia. Interdiscurso. Memoria Discursiva. Narrativa Periodística. 


\section{Expediente}

A revista E-Compós é a publicação científica em formato eletrônico da Associação Nacional dos Programas de Pós-Graduação em Comunicação (Compós). Lançada em 2004, tem como principal finalidade difundir a produção acadêmica de pesquisadores da área de Comunicação, inseridos em instituições do Brasil e do exterior.
E-COMPÓS I www.e-compos.org.br I E-ISSN 1808-2599

Revista da Associação Nacional dos Programas

de Pós-Graduação em Comunicação.

Brasília, v.15, n.1, jan./abr. 2012.

A identificação das edições, a partir de 2008

passa a ser volume anual com três números.

\section{CONSELHO EDITORIAL}

Afonso Albuquerque, Universidade Federal Fluminense, Brasil Alberto Carlos Augusto Klein, Universidade Estadual de Londrina, Brasil Álvaro Larangeira, Universidade Tuiuti do Paraná, Brasil Ana Carolina Damboriarena Escosteguy, Pontifícia Universidade Católica do Rio Grande do Sul, Brasil

Ana Gruszynski, Universidade Federal do Rio Grande do Sul, Brasil Ana Silvia Lopes Davi Médola, Universidade Estadual Paulista, Brasil André Luiz Martins Lemos, Universidade Federal da Bahia, Brasil Ângela Freire Prysthon, Universidade Federal de Pernambuco, Brasil Angela Cristina Salgueiro Marques, Faculdade Cásper Líbero (São Paulo), Brasil Antônio Fausto Neto, Universidade do Vale do Rio dos Sinos, Brasil Antonio Carlos Hohlfeldt, Pontifícia Universidade Católica do Rio Grande do Sul, Brasil Antonio Roberto Chiachiri Filho, Faculdade Cásper Líbero, Brasil Arthur Autran Franco de Sá Neto, Universidade Federal de São Carlos, Brasil Benjamim Picado, Universidade Federal Fluminense, Brasil César Geraldo Guimarães, Universidade Federal de Minas Gerais, Brasil Cristiane Freitas Gutfreind, Pontifícia Universidade Católica do Rio Grande do Sul, Brasil Denilson Lopes, Universidade Federal do Rio de Janeiro, Brasil Eduardo Peñuela Cañizal, Universidade Paulista, Brasil Eduardo Vicente, Universidade de São Paulo, Brasil Eneus Trindade, Universidade de São Paulo, Brasil Erick Felinto de Oliveira, Universidade do Estado do Rio de Janeiro, Brasil Florence Dravet, Universidade Católica de Brasilia, Brasil Gelson Santana, Universidade Anhembi/Morumbi, Brasil Gislene da Silva, Universidade Federal de Santa Catarina, Brasil Guillermo Orozco Gómez, Universidad de Guadalajara Gustavo Daudt Fischer, Universidade do Vale do Rio dos Sinos, Brasil Hector Ospina, Universidad de Manizales, Colômbia Herom Vargas, Universidade Municipal de São Caetano do Sul, Brasil leda Tucherman, Universidade Federal do Rio de Janeiro, Brasil Inês Vitorino, Universidade Federal do Ceará, Brasil Jnice Caiafa, Universidade Federal do Rio de Janeiro, Brasil Jay David Bolter, Georgia Institute of Technology Jeder Silveira Janotti Junior, Universidade Federal de Pernambuco, Brasil João Freire Filho, Universidade Federal do Rio de Janeiro, Brasil John DH Downing, University of Texas at Austin, Estados Unidos José Afonso da Silva Junior, Universidade Federal de Pernambuco, Brasil
José Carlos Rodrigues, Pontifícia Universidade Católica do Rio de Janeiro, Brasil José Luiz Aidar Prado, Pontifícia Universidade Católica de São Paulo, Brasil José Luiz Warren Jardim Gomes Braga, Universidade do Vale do Rio dos Sinos, Brasil Juremir Machado da Silva, Pontifícia Universidade Católica do Rio Grande do Sul, Brasil Laan Mendes Barros, Universidade Metodista de São Paulo, Brasil Lance Strate, Fordham University, USA, Estados Unidos Lorraine Leu, University of Bristol, Grã-Bretanha Lucia Leão, Pontifícia Universidade Católica de São Paulo, Brasil Malena Segura Contrera, Universidade Paulista, Brasil Márcio de Vasconcellos Serelle, Pontifícia Universidade Católica de Minas Gerais, Brasil Maria Aparecida Baccega, Universidade de São Paulo e Escola Superior de Propaganda e Marketing, Brasil Maria das Graças Pinto Coelho, Universidade Federal do Rio Grande do Norte, Brasil Maria Immacolata Vassallo de Lopes, Universidade de São Paulo, Brasil Maria Luiza Martins de Mendonça, Universidade Federal de Goiás, Brasil Mauro de Souza Ventura, Universidade Estadual Paulista, Brasil Mauro Pereira Porto, Tulane University, Estados Unidos Mirna Feitoza Pereira, Universidade Federal do Amazonas, Brasil Nilda Aparecida Jacks, Universidade Federal do Rio Grande do Sul, Brasil Paulo Roberto Gibaldi Vaz, Universidade Federal do Rio de Janeiro, Brasil Potiguara Mendes Silveira Jr, Universidade Federal de Juiz de Fora, Brasil Renato Cordeiro Gomes, Pontifícia Universidade Católica do Rio de Janeiro, Brasil Robert K Logan, University of Toronto, Canadá

Ronaldo George Helal, Universidade do Estado do Rio de Janeiro, Brasil Rose Melo Rocha, Escola Superior de Propaganda e Marketing, Brasil Rossana Reguillo, Instituto de Estudos Superiores do Ocidente, Mexico Rousiley Celi Moreira Maia, Universidade Federal de Minas Gerais, Brasil Sebastião Carlos de Morais Squirra, Universidade Metodista de São Paulo, Brasil Sebastião Guilherme Albano da Costa, Universidade Federal do Rio Grande do Norte, Brasil

Simone Maria Andrade Pereira de Sá, Universidade Federal Fluminense, Brasil Tiago Quiroga Fausto Neto, Universidade de Brasília, Brasil

Suzete Venturelli, Universidade de Brasilia, Brasil Valério Cruz Brittos, Universidade do Vale do Rio dos Sinos, Brasil Valerio Fuenzalida Fernández, Puc-Chile, Chile Veneza Mayora Ronsini, Universidade Federal de Santa Maria, Brasil Vera Regina Veiga França, Universidade Federal de Minas Gerais, Brasil

\section{COMISSÃO EDITORIAL}

Adriana Braga I Pontifícia Universidade Católica do Rio de Janeiro, Brasil

Felipe Costa Trotta I Universidade Federal Fluminense, Brasil

CONSULTORES AD HOC

Bruno Campanella, Universidade Federal Fluminense, Brasil

Gisela Grangeiro da Silva Castro, Escola Superior de Propaganda e Marketing, Brasi José Carlos Ribeiro, Universidade Federal da Bahia, Brasil

Luciana Panke, Universidade Federal do Paraná, Brasil

Micael Herschmann, Universidade Federal do Rio de Janeiro, Brasil

Tânia Márcia Cezar Hoff, Escola Superior de Propaganda e Marketing, Brasil

Virginia da Silveira Fonseca, Universidade Federal do Rio Grande do Sul, Brasil

EDIÇÃO DE TEXTO E RESUMOS I Susane Barros

SECRETÁRIA EXECUTIVA I Juliana Depiné

EDITORAÇÃO ELETRÔNICA I Roka Estúdio
COMPós I www.compos.org.br

Associação Nacional dos Programas de Pós-Graduação em Comunicação

Presidente

Julio Pinto

Pontifícia Universidade Católica de Minas Gerais, Brasil

juliopinto@pucminas.br

Vice-presidente

Itania Maria Mota Gomes

Universidade Federal da Bahia, Brasil

itania@ufba.br

Secretária-Geral

Inês Vitorino

Universidade Federal do Ceará, Brasil

inesvict@gmail.com 